\title{
Radiology
}

\section{Potential of Routine X-ray Examinations in Detecting Signs of Asymptomatic Carotid Disease}

\author{
Maria S. Starodubtseva, $\mathrm{PGS}^{1}$; Dmitry A. Lezhnev, $\mathrm{MD}, \mathrm{PhD}, \mathrm{ScD}^{1}$; \\ Aleksandr Yu. Vasilyev, MD, PhD, ScD ${ }^{1,2}$; Igor D. Stulin, MD, PhD, ScD ${ }^{1}$; Sergey A. \\ Trukhanov, $\mathrm{MD}, \mathrm{PhD}^{1}$; Elena A. Egorova, $\mathrm{MD}, \mathrm{PhD}, \mathrm{ScD}^{1}$; Victor P. Truten, $\mathrm{MD}, \mathrm{PhD}, \mathrm{ScD}^{1}$; \\ Margarita V. Smyslenova, MD, $\mathrm{PhD}, \mathrm{ScD}^{1}$; Victoriya V. Petrovskaya, $\mathrm{MD}, \mathrm{PhD}^{1}$ \\ ${ }^{\prime}$ Moscow State University of Medicine and Dentistry, Moscow, Russia \\ ${ }^{2}$ Central Research Institute of Radiation Diagnostics, Moscow, Russia
}

\begin{abstract}
Background: The aim of our study was to determine potential opportunities for routine radiological examinations (dental panoramic radiography (DPR), cervical spine radiography (CSR), cone beam computed tomography (CBCT) and multislice computed tomography (MSCT)) in the identification of carotid artery calcifications (CAC) as radiological signs of asymptomatic carotid artery disease (ACAD).

Methods and Results: The retrospectively evaluated results of the digital DPR were used for 4367 patients, CSR - 857 patients, CBCT - 582 patients, and MSCT - 377 patients. Mean age of patients was more than 55 years. The overall detectability of CAC during DPR, CSR, CBCT, and MSCT was $8.3 \%, 15.9 \%, 13.1 \%$, and $40.6 \%$, respectively. The gender difference in favor of women was observed during DPR, CBCT and MSCT and in favor of men - only during CSR. CAC should be sought at the level of C3-C4 intravertebral discs in the cervical soft tissues, more often on the one side, in the form of solitary/multiple, friable, homogenous/heterogeneous radiopaque shadows smaller than $0.5 \mathrm{~cm}$.

Conclusion: $\mathrm{CAC}$ indicates the presence of a high risk of developing ischemic stroke, which means that the above modalities have to be used as a tool to identify the predictor of this pathological condition of the cardiovascular system. (International Journal of Biomedicine. 2020;10(1):36-40.)
\end{abstract}

Key Words: carotid artery calcifications $\bullet$ screening $\bullet$ radiological examinations $\bullet$ ischemic stroke

\section{Abbreviations}

ACAD, asymptomatic carotid artery disease; BCA, brachiocephalic artery; CBCT, cone beam computed tomography; CAC, carotid artery calcifications; CSR, cervical spine radiography; DPR, dental panoramic radiography; MSCT, multislice computed tomography; US, ultrasound

\section{Introduction}

Asymptomatic carotid artery disease (ACAD) is a disorder identified in people who did not have either a previous history of ischemic stroke or transient ischemic attack in the ipsilateral carotid artery area with neurological signs, such

"Corresponding author: Prof. Alexander Yu. Vasilyev, MD, PhD, ScD. Department of Radiology, Moscow State University of Medicine and Dentistry named after A. I. Evdokimov, Moscow, Russia.E-mail: $\underline{\text { auv62@mail.ru }}$ as transient blindness, fatigue, numbness in the extremities or contralateral side of the face, dysarthria or aphasia over the past six months..$^{(1-2)}$ The underlying cause of ACAD is an atherosclerotic lesion of the vascular wall. At certain stages of atherosclerotic plaque formation, the lesion can be accompanied by vascular calcinosis due to the deposition of calcium salts; the plaque becomes radiopaque and it results in the appearance of carotid artery calcifications (CAC). ${ }^{(3)}$

Routine examinations, including radiological ones, are widely available, inexpensive, standardized and diagnostic; they are also frequently applied and performed due to numerous 
indications. ${ }^{(4)}$ According to the WHO, more than $60 \%$ of radiological examinations are dental. ${ }^{(5)}$ The data obtained in 2017 showed that tens of thousands of cervical spine radiographs and dental panoramic radiographs are performed annually in Russia. ${ }^{(6)}$ Moreover, computed tomography (both $\mathrm{CBCT}$ and MSCT) is no longer an exotic radiological method available only in extreme cases and for specific indications. Nowadays, this is a routine radiological procedure in our country, which is normally applied for diagnosing different types of problems. ${ }^{(7)}$

All the above-mentioned statistical data and regulations allow us to consider dental panoramic radiography (DPR), cervical spine radiography (CSR), cone beam computed tomography (CBCT), and multislice computed tomography (MSCT) as routine radiological examinations.

The first mention of using of X-ray methods of examinations for the detection of CCA dates back to 1912, when Schuller, in his published monograph, indicated the possibility of detecting calcifications of "vascular" origin during X-ray of the skull. ${ }^{(8)}$

Later in 1951, Fisher M., in an article about the occlusion of carotid arteries, mentioned the possibility of detecting linear shadows of calcifications in the projection of the bulb of the internal carotid artery during radiography of the cervical spine. ${ }^{(9)}$

In 1963, Ring and Eddy published an article in which they evaluated 1000 chest radiographs and identified 216 cases of CAC. The detection rate was noted to be higher in elderly people, and in a group of patients over 80 years of age, CAC was revealed in more than $70 \%$ of cases. ${ }^{(10)}$ In addition, in 1963, Hayler and Fischer were the first to use CSR for detecting CAC. . $^{(1)}$

In Russia, the pioneer and certainly the best expert on the problem in those years, was L.K. Bragina (1962), who carefully compared various invasive and non-invasive methods of X-ray diagnosis.

Since the 1970s, numerous studies of Stulin et al., dedicated to screening clinical and instrumental examinations, showed the possibility and perspective of identifying extraand intracerebral atherosclerosis, often combined with coronary atherosclerosis. ${ }^{(12,13)}$

In 1981, Friedlander and Lande identified CAC for the first time in dental panoramic radiograms, which were performed in general dental practice. The authors paid attention to the fact that DPR should be performed for detecting dental abnormalities, pathologies of the temporomandibular joint and adjacent structures. Special focus should be given to the peripheral areas in the projection of the common carotid artery, which may provide the vital information. ${ }^{(14)}$

Since that time, there has been an increasing interest in the issue, and groups of scientists all over the world have been actively involved in its research.

The aim of our study was to determine potential opportunities for routine radiological examinations (DPR, CSR, CBCT and MSCT) in the identification of CAC as radiological signs of ACAD. defined:
1.To analyze the current status of diagnosing ACAD.

2.To carry out a retrospective analysis of the results of routine radiological examinations (DPR, CSR, CBCT, and MSCT).

3.To evaluate the opportunities for routine radiological techniques (DPR, CSR, CBCT, MSCT) in the visualization of CAC.

4.To study and to specify radiological changes in CAC as radiological signs of ACAD.

5.To specify radiological signs of anatomic and pathological structures that are necessary for differentiation of CAC.

6.To improve and to complete the algorithm for analysis of the results of routine radiological examinations in diagnosis of carotid artery atherosclerosis as ACAD manifestation.

\section{Materials and Methods}

During the first stage of the study, we performed a retrospective evaluation of the results of digital DPR (Group 1) in 4637 patients (mean age of $66.1 \pm 8.6$ years), digital CSR (Group 2) in 857 patients (mean age of $61.7 \pm 6.4$ years), CBCT (Group 3) in 582 patients (mean age of $63.2 \pm 6.9$ years), and MSCT (Group 4) of lower facial zone and neck in 377 patients (mean age $65.1 \pm 7.5$ years).

A total of 6453 results were retrospectively evaluated. All patients in each group were divided into the following age subgroups: 55-59 years, 60-64 years, 65-69 years, 70-74 years, $75-79$ years, and over 80 years.

Inclusion criteria were patient's age over 55 years, the absence of neurological signs of ACAD for the past 6 months minimum, according to the patient's previous history, and the possibility of visualizing cervical soft tissues.

Exclusion criteria were patient's age under 55 years, the presence of neurological signs of ACAD, according to the patient's previous history, the absence of visualization of cervical soft tissues due to the insufficient area of investigation and/or wrong physical and technical parameters of the examination.

During the second stage of the study, we evaluated the previous histories of all patients in the first and second groups in order to identify those patients who underwent a US examination of BCA within a year after the radiological examination. The US of BCA is considered to be a gold standard in radiological diagnosis of atherosclerotic lesions of the carotid arteries in patients without neurological symptoms. If the patients underwent the US of BCA within a year, its protocol and conclusion were assessed to determine the presence or absence of evidence of calcified atherosclerotic plaques located in the carotid arteries. The obtained data were compared with the findings received after the first stage of the study in order to evaluate diagnostic effectiveness of radiological examinations.

Among 4637 patients included in Group 1, 1523(32.8\%) patients had US of BCA in their histories. Patients who underwent US of BCA later than DPR were selected first from this group; their number was 289 people, including 183 patients who underwent US of BCA within a year after DPR. The protocols of US of BCA of these 183 patients were chosen for the final analysis, which allowed us to evaluate the diagnostic effectiveness of DPR in revealing CAC. 
Among 857 patients composing Group 2, 271(31.6\%) people had US of BCA in their histories. All these patients had US of BCA within a year after CSR, and due to this fact, they were all included in the final analysis for evaluation of indicators of CSR diagnostic effectiveness in detecting CAC.

\section{Results}

Normality of distribution by age was determined for each group. As the number of investigations exceeded 50 in each case, a one-sample Kolmogorov-Smirnov test was applied for this purpose, and additionally, skewness and kurtosis parameters were evaluated.

For all four techniques the obtained findings of significance level were $<0.05$, skewness and kurtosis parameters were not equal to 0 , which allowed us to consider the distribution for each of the groups as different from normal and to apply nonparametric statistical methods in statistical processing (odds ratio (OR), Fischer's exact test).

Total detection rate of the patients with suspected CAC using DPR was $8.3 \%$ (mean age of $66.7 \pm 8.7$ years, ratio of men to women was 2.8:1), using CSR it was $15.9 \%$ (mean age of $64.9 \pm 7.3$, ratio of men to women was $0.8: 1$ ), using CBCT it was $13.1 \%$ (mean age of $66.4 \pm 7.7$, ratio of men to women was $1.8: 1$ ), and for MSCT it was $40.6 \%$ (mean age of $67.9 \pm 7.3$, ratio of men to women was 1.3:1).

Moreover, the odds ratio parameters and Fischer's exact test were estimated for each radiological technique: The parameters for DPR, CSR, CBCT and MSCT were 1.848 (95\% CI: 1.462-2.335; $P<0.001$ ), 0.358 (95\% CI: 0.247-0.520; $P<0.001), 0.768$ (95\% CI:0.462-1.277; $P=0.346$ ), and 0.518 (95\% CI: 0.336-0.800; $P=0.04$ ), respectively.

During the second stage of the study, the data of routine radiological examinations and US of BCA were compared and the following groups of findings were identified:

1. True-positive findings. The data of retrospective analysis of DPR or CSR on CAC presence were consistent with the protocol of US of BCA, proving the evidence of calcified atherosclerotic plaques in the carotid arteries.

The indicator of true-positive results was 12 for DPR, and 37 for CSR.

2. False-positive findings. The data of retrospective analysis of DPR or CSR showed the presence of CAC, but according to the protocols of the US of BCA, there were not any atherosclerotic plaques in the carotid arteries.

The indicator of false-positive results was 8 for DPR, and 6 for CSR.

3. False-negative findings. The retrospective analysis of DPR or CSR did not reveal any pathological changes suggesting the presence of CAC; however, calcified atherosclerotic plaques in the carotid arteries were detected using the US of BCA, according to the protocols.

The indicator of false-negative results was 6 for DPR, and 13 for CSR.

4. True-negative findings. The data of retrospective analysis of DPR or CSR on the absence of CAC were consistent with the protocol of US of BCA, proving the absence of calcified atherosclerotic plaques in the carotid arteries.
The indicator of true-negative results was 157 for DPR, and 213 for CSR.

Based on the above-mentioned findings, we estimated sensitivity, specificity and accuracy parameters for DPR and CSR, which were $66.7 \%, 95.1 \%$, and $92.3 \%$ and $71.2 \%$, $97.3 \%$, and $92.2 \%$, respectively.

The next stage of our research was the evaluation of radiological characteristics of CAC signs on the basis of DPR, CSR, CBCT and MSCT findings, in order to reveal the most common characteristics of the following parameters (Table 1, Figure 1):

- Level of CAC location toward the cervical vertebrae

- Side of location (left-sided, right-sided, located on each side from the cervical spine)

- Intensity (hardly visible, moderately dense, pronounced calcifications)

- Number (solitary, multiple)

- Shape (linear, annual, friable)

- Structure (homogeneous, heterogenous)

- Size $(<0.5 \mathrm{~cm}$, from 0.5 to $1 \mathrm{~cm},>1 \mathrm{~cm})$

Table 1

Radiological characteristics of CAC

\begin{tabular}{|l|c|c|c|c|}
\hline & DPR & CSR & CBCT & MSCT \\
\hline $\begin{array}{l}\text { Level of } \\
\text { location }\end{array}$ & $\begin{array}{c}\text { C3-C4 (34\%) } \\
\text { C4 (34\%) }\end{array}$ & $\begin{array}{c}\text { C3-C4 }(37.5 \%) \\
\text { C4-C5 }(25.8 \%)\end{array}$ & $\begin{array}{c}\text { C3-C4 }(39.5 \%) \\
\text { C4 }(31.6 \%) \\
\text { C3 }(19.7 \%)\end{array}$ & $\begin{array}{c}\text { C3-C4(32.7\%) } \\
\text { C4 }(24.8 \%) \\
\text { C3 }(24.2 \%)\end{array}$ \\
\hline $\begin{array}{l}\text { Side of } \\
\text { location }\end{array}$ & $\begin{array}{c}\text { Unilateral } \\
(76.1 \%)\end{array}$ & $\begin{array}{c}\text { Unilateral } \\
(76.5 \%)\end{array}$ & $\begin{array}{c}\text { Unilateral } \\
(81.6 \%)\end{array}$ & $\begin{array}{c}\text { Unilateral } \\
(50.3 \%)\end{array}$ \\
\hline Intensity & $\begin{array}{c}\text { Moderately } \\
\text { dense } \\
(89.1 \%)\end{array}$ & $\begin{array}{c}\text { Moderately } \\
\text { dense (76.5\%) }\end{array}$ & $\begin{array}{c}\text { Moderately } \\
\text { dense } \\
(78.9 \%)\end{array}$ & $\begin{array}{c}\text { Moderately } \\
\text { dense } \\
(85.6 \%)\end{array}$ \\
\hline Number & $\begin{array}{c}\text { Solitary } \\
(57.9 \%)\end{array}$ & $\begin{array}{c}\text { Solitary } \\
(66.2 \%)\end{array}$ & $\begin{array}{c}\text { Solitary } \\
(57.9 \%)\end{array}$ & $\begin{array}{c}\text { Multiple } \\
(64.1 \%)\end{array}$ \\
\hline Shape & $\begin{array}{c}\text { Friable } \\
(87.2 \%)\end{array}$ & $\begin{array}{c}\text { Friable } \\
(83.1 \%)\end{array}$ & $\begin{array}{c}\text { Friable } \\
(73.7 \%)\end{array}$ & $\begin{array}{c}\text { Friable } \\
(78.5 \%)\end{array}$ \\
\hline Structure & $\begin{array}{c}\text { Homo- } \\
\text { geneous } \\
(51.4 \%)\end{array}$ & $\begin{array}{c}\text { Hetero- } \\
\text { geneous } \\
(50.1 \%)\end{array}$ & $\begin{array}{c}\text { Homo- } \\
\text { geneous } \\
(61.8 \%)\end{array}$ & $\begin{array}{c}\text { Hetero- } \\
\text { geneous } \\
(62.1 \%)\end{array}$ \\
\hline Size & $\begin{array}{c}\text { Smaller than } \\
0.5 \text { cm (74\%) }\end{array}$ & $\begin{array}{c}\text { Smaller than } \\
0.5 \text { cm (66.9\%) }\end{array}$ & $\begin{array}{c}\text { Smaller than } \\
0.5 \text { cm (84.2\%) }\end{array}$ & $\begin{array}{c}\text { Smaller than } \\
\text { (5.5 cm (70.6\%) }\end{array}$ \\
\hline
\end{tabular}

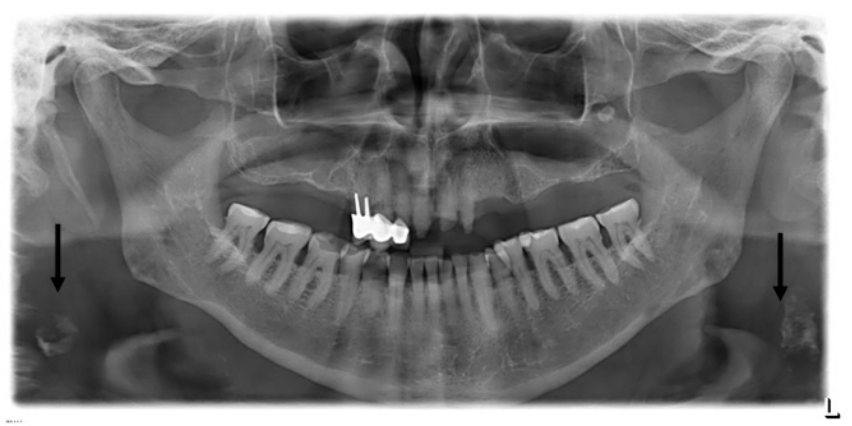

Fig. 1. DPR. Heterogeneous moderately dense radiopaque shadows, semicircular on the right and linear on the left, with the diameter of $15.0 \mathrm{~mm}$ and length of $16.0 \mathrm{~mm}$, respectively (arrows). They can be visualized on both sides closer to the cervical spine in the cervical soft tissues. 
It is worth noting that while performing two-dimensional investigations (DPR and CSR) it is necessary to differentiate CAC from various calcified anatomical and pathological structures. In our research, we used a dental panoramic radiogram for this purpose.

Among 4637 patients, 282(6.1\%) had solitary/multiple calcifications in the soft tissues of the head and neck; they were revealed by dental panoramic radiograms. Table 2 shows the distribution of these calcifications.

Table 2.

Revealed calcifications in the soft tissues of the head and neck using DPR

\begin{tabular}{|l|c|c|c|}
\hline \multicolumn{1}{|c|}{$\begin{array}{c}\text { Anatomical/pathological } \\
\text { structure }\end{array}$} & $\begin{array}{c}\text { Absolute } \\
\text { number of } \\
\text { patients }\end{array}$ & $\begin{array}{c}\text { \% of total } \\
\text { number of } \\
\text { patients with } \\
\text { calcifications }\end{array}$ & $\begin{array}{c}\text { \% of total } \\
\text { number of } \\
\text { patients in } \\
\text { the study } \\
\text { (DPR) }\end{array}$ \\
\hline Calcified triticeal cartilage & 84 & 29.8 & 1.8 \\
\hline $\begin{array}{l}\text { Calcified stylohyoid ligament } \\
\text { unilateral/bilateral }\end{array}$ & 9 & 3.2 & 0.2 \\
\hline $\begin{array}{l}\text { Calcified stylomandibular } \\
\text { ligament unilateral/bilateral }\end{array}$ & 9 & 3.2 & 0.2 \\
\hline $\begin{array}{l}\text { Parotid gland calculi } \\
\text { unilateral/bilateral }\end{array}$ & 66 & 23.4 & 1.4 \\
\hline $\begin{array}{l}\text { Submandibular gland calculi } \\
\text { unilateral/bilateral }\end{array}$ & 44 & 15.6 & 0.9 \\
\hline Calcified lymph node & 7 & 2.5 & 0.1 \\
\hline Vascular stent & 5 & 1.8 & 0.1 \\
\hline $\begin{array}{l}\text { Calculi in the parotid and } \\
\text { submandibular salivary glands }\end{array}$ & 1 & 0.4 & 0.02 \\
\hline $\begin{array}{l}\text { Idiopathic calculi } \\
\text { (solitary/multiple) }\end{array}$ & 57 & 20.1 & 1.2 \\
\hline
\end{tabular}

\section{Discussion}

CAC can be revealed during routine radiological investigations (DPR, CSR, CBCT and MSCT) that allow us to use them as examinations for the primary detection of ACAD. According to different authors, the total detection rate of CAC using DPR ranges from $0.43 \%{ }^{(15)}$ to $38.8 \%,{ }^{(16)}$ and using CSR it is $13.0 \%{ }^{(17)}$ In our research, the total detection rate of CAC for DPR, CSR, CBCT and MSCT was 8.3\%, 15.9\%, 13.1\% and $40.6 \%$, respectively.

Many researchers emphasize that most of the patients with CAC are women. ${ }^{(18-21)}$ In our study, CAC was more frequently detected in women than in men while using three out of four radiological techniques (DPR $-73.8 \%$, CBCT $-64.5 \%$, MSCT $-57.5 \%)$. However, this association turned out to be statistically significant only for DPR (OR=1.848, 95\% CI: $1.462-2.235$, $P<0.001)$. For CBCT this association was not statistically significant $(\mathrm{OR}=0.768,95 \% \mathrm{CI}$ : 0.462-1.277, $P=0.346)$. CSR, as the primary diagnostic technique in ACAD, was used only in one scientific work, but there was not any indication of the gender ratio among the patients with $\mathrm{CAC} \cdot{ }^{(17)}$ In our study, using CSR investigation, we revealed more male patients with CAC, and this association was statistically significant $(\mathrm{OR}=0.358$, 95\% CI: $0.247-0.520 ; P<0.001)$.
Diagnostic effectiveness indicators of two-dimensional routine radiological techniques were evaluated by many researchers. Yoon et al. ${ }^{(22)}$ estimated the sensitivity, specificity and accuracy of DPR as $22.2 \%, 62.3 \%$ and $90.0 \%$, respectively; Alman et al. ${ }^{(23)}$ assessed sensitivity and specificity as $77.8 \%$ and $84.0 \%$; Khambete et al. ${ }^{(24)}-$ as $76.0 \%$ and $98.66 \%$; Constantine et al. ${ }^{(25)}$ - as $76.9 \%$ and $46.9 \%$. In our research, sensitivity, specificity and accuracy of DPR were determined as $66.7 \%, 95.1 \%$ and $92.3 \%$, respectively; CSR $-71.2 \%$, $97.3 \%$ and $92.2 \%$, respectively.

Based on the obtained data of DPR, CSR, CBCT and MSCT, we determined that the most frequent significant radiological signs of CAC were presented by unilateral, moderately dense, solitary/multiple, friable, homogenous/ heterogeneous radiopaque shadows smaller than $0.5 \mathrm{~cm}$ in the cervical soft tissues at the level of the $\mathrm{C} 3-\mathrm{C} 4$ intravertebral discs (Figure 1).

It is necessary to differentiate CAC from other anatomical and pathological structures; the most frequent anatomical one is calcified triticeal cartilage $(n=84,29.8 \%)$, and the most common pathological structure is parotid gland calculus ( $\mathrm{n}=66,23.4 \%$ ) (Figure 2). The obtained findings are consistent with the data of foreign researchers. ${ }^{(26-30)}$

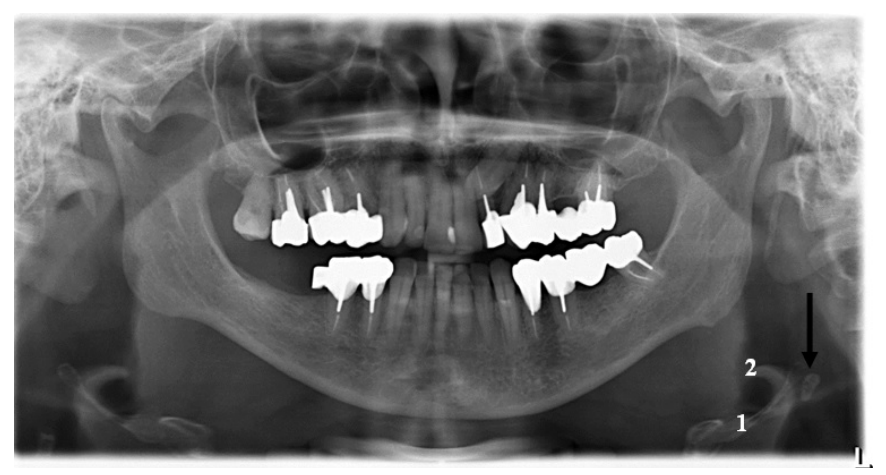

Fig. 2. DPR. Solitary radiopaque oval-shaped shadow with welldefined smooth edges can be visualized in the cervical soft tissues on the left under the great horn of hyoid bone (1) and epiglottis (2). The shadow may refer to calcified triticeal cartilage (arrow).

Thus, carotid artery calcifications suggest the presence of atherosclerosis of the particular localization and consequently the presence of high risk for developing ischemic stroke; hence, the above-mentioned techniques (DPR, CSR, CBCT, MSCT) have to be used as an instrument for detecting a predictor of this socially and economically significant pathological condition of the cardiovascular system.

\section{Acknowledgements}

We express our gratitude and deep appreciation to Dmitriy A. Lezhnev, Doctor of Medicine, Professor, Head of Radiology Department of the Moscow State University of Medicine and Dentistry, for the valuable advice and comments.

\section{Competing Interests}

The authors declare that they have no competing interests. 


\section{References}

1. Garoff M, Johansson E, Ahlqvist J, Jäghagen EL, Arnerlöv C, Wester P. Detection of calcifications in panoramic radiographs in patients with carotid stenoses $\geq 50 \%$. Oral Surg Oral Med Oral Pathol Oral Radiol. 2014;117(3):385-91. doi: 10.1016/j.oooo.2014.01.010.

2. Yuan G, Zhou S, Wu W, Zhang Y, Lei J, Huang B. Carotid Artery Stenting Versus Carotid Endarterectomy for Treatment of Asymptomatic Carotid Artery Stenosis. Int Heart J. 2018;59(3):550-558. doi: 10.1536/ihj.17-312.

3. Friedlander AH. Recognizing calcifications of the carotid artery on panoramic radiographs to prevent strokes. Schweiz Monatsschr Zahnmed. 2013;123(6):545.

4. World Health Organization. (2017)! Guide to cancer early diagnosis. World Health Organization. https://apps.who.int/ iris/handle/10665/254500.

5. Hafizov RG, Zhitko AK, Azisova DA, Hafizova FA, Khayrutdinova AR. Dental radiology. Teaching aid. Kazan; 2015.

6. Stulin ID, Boytsov SA, Vasiliev AYu. [A new look at the diagnosis of atherocalcinosis of the carotid arteries]. Moscow Medicine. 2017;21(S2):99. [Article in Russian].

7. Webb UR, Brant WE, Major NM. Computed tomography: chest, abdomen and pelvis, musculoskeletal system. M.: GEOTAR-Media; 2018.

8. Shüller A. Röntgendiagnostik der erkrankungen des kopfes. Wien, Leipzig: Ho“lder; 1912.

9. Fisher M. Occlusion of the internal carotid artery. AMA Arch Neurol Psychiatry. 1951;65(3):346-77.

10. Ring BA, Eddy WM. Calcification of carotid arteries. Routine radiographs of the chest. JAMA. 1963;184:866-9.

11. Hayler K, Fischer E. Karotisverkalkungen im Halsgebiet. Fortschr. Röntgenstr. 1963;99:765-772.

12. Stulin ID, Vasiliev AYu, Belousov YuB. [Roentgenography of the cervical spine to detect atherosclerosis of the carotid and vertebral arteries]. Zhurnal Nevrologii i Psikhiatrii. 2006;(16):35-40. [Article in Russian].

13. Stulin ID, Buziashvili YuI, Vasiliev AYu, Boytsov SA, Trukhanov SA, Solonsky DS. [Radiological techniques in the primary diagnosis of atherosclerotic disease of the carotid arteries. Is it possible to expand the diagnostic capabilities of "routine" screening?] Kremlin Medicine Journal. 2018;(3):1722. [Article in Russian].

14. Friedlander AH, Lande A. Panoramic radiographic identification of carotid arterial plaques. Oral Surg Oral Med Oral Pathol. 1981;52(1):102-4.

15. Hubar JS. Carotid artery calcification in the black population: a retrospective study on panoramicradiographs. Dentomaxillofac Radiol. 1999;28(6):348-50.

16. Uthman AT, Al-Saffar AB. Prevalence in digital panoramic radiographs of carotid area calcification among Iraqi individuals with stroke-related disease. Oral Surg Oral Med Oral Pathol Oral Radiol Endod. 2008;105(4):e68-73. doi: 10.1016/j.tripleo.2007.11.009.

17. Stulin ID, Buziashvili YuI, Vasiliev AYu, Boytsov SA, Drapkina OM, Gusev EI, et al. [Possibilities of digital fluorography and other X-ray methods in the detection of carotid atherosclerosis]. S.S. Korsakov Journal of Neurology and Psychiatry. 2019; 119(8): 38-45. [Article in Russian].
18. Ariayi AS, Berndt D, Lambrecht JT. [Soft tissue calcifications in panoramic radiography. A risk factor for cerebrovascular accidents?]. Schweiz Monatsschr Zahnmed. 2009;119(10):1009-18. [Article in French, German]

19. Barona-Dorado C, Gutierrez-Bonet C, Leco-Berrocal I, Fernández-Cáliz F, Martínez-González JM. Relation between diagnosis of atheromatous plaque from orthopantomographs and cardiovascular risk factors. A study of cases and control subjects. Med Oral Patol Oral Cir Bucal. 2016;21(1):e66-e71. 20. Bayram B, Uckan S, Acikgoz A, Müderrisoglu H, Aydinalp A. Digital panoramic radiography: a reliable method to diagnose carotid artery atheromas?. Dentomaxillofac Radiol. 2006;35(4):266-70.

21. Brand HS, Mekenkamp WC, Baart JA. [Prevalence of carotid artery calcification on panoramic radiographs]. Ned Tijdschr Tandheelkd. 2009;116(2):69-73. [Article in Dutch]. 22. Yoon SJ, Yoon W, Kim OS, Lee JS, Kang BC. Diagnostic accuracy of panoramic radiography in the detection of calcified carotid artery. Dentomaxillofac Radiol. 2008;37(2):104-8. doi: $10.1259 / \mathrm{dmfr} / 86909790$.

23. Alman AC1, Johnson LR, Calverley DC, Grunwald GK, Lezotte DC, Hokanson JE. Validation of a method for quantifying carotid artery calcification from panoramic radiographs. Oral Surg Oral Med Oral Pathol Oral Radiol. 2013;116(4):518-24. doi: 10.1016/j.oooo.2013.06.026.

24. Khambete N, Kumar R, Risbud M, Joshi A. Reliability of digital panoramic radiographs in detecting calcified carotid artery atheromatous plaques: a clinical study. Indian J Dent Res. 2014;25(1):36-40. doi: 10.4103/0970-9290.131052.

25. Constantine S, Roach D, Liberali S, Kiermeier A, Sarkar P, Jannes J, et al. Carotid Artery Calcification on Orthopantomograms (CACO Study) - is it indicative of carotid stenosis? Aust Dent J. 2019;64(1):4-10. doi: 10.1111/ adj. 12651.

26. Villoria EM, Souki BQ, Antunes FL, Castro IK, Spyrides KS, Soares RV. Panoramic radiography and cone beam computed tomography in the early diagnosis of atheroma in the extracranial and intracranial carotid artery: A case report. Int J Odontostomat. 2019;13(1):75-81.

27. Gustafsson N, Ahlqvist JB, Näslund U, Wester P, Buhlin $\mathrm{K}$, Gustafsson A, Levring Jäghagen E. Calcified carotid artery atheromas in panoramic radiographs are associated with a first myocardial infarction: a case-control study. Oral Surg Oral Med Oral Pathol Oral Radiol. 2018;125(2):199-204.e1. doi: 10.1016/j.oooo.2017.10.009.

28. Nasseh I, Aoun G. Carotid Artery Calcification: A Digital Panoramic-Based Study. Diseases. 2018;6(1). pii: E15. doi: 10.3390/diseases6010015.

29. Ribeiro A, Keat R, Khalid S, Ariyaratnam S, Makwana M, do Pranto M, Albuquerque R, Monteiro L. Prevalence of calcifications in soft tissues visible on a dental pantomogram: A retrospective analysis. J Stomatol Oral Maxillofac Surg. 2018;119(5):369-374. doi: 10.1016/j.jormas.2018.04.014.

30. Sutter W, Berger S, Meier M, Kropp A, Kielbassa AM, Turhani D. Cross-sectional study on the prevalence of carotid artery calcifications, tonsilloliths, calcified submandibular lymph nodes, sialoliths of the submandibular gland, and idiopathic osteosclerosis using digital panoramic radiography in a Lower Austrian subpopulation. Quintessence Int. 2018 Jan 22:231-242. doi: 10.3290/j.qi.a39746. 